\title{
Expectation Formation and Endogenous Fluctuations in Aggregate Demand
}

\author{
Maciej K. Dudek*
}

December 24, 2003

\begin{abstract}
A bstract
The paper recognizes that expectations and the process of their formation are subject to standard decision making and are determined as a part of equilibrium. Accordingly, the paper presents a basic framework in which the form of expectation formation is a choice variable. At any point in time rational economic agents decide on the basis of the level of utility what expectation formation technology to use and as a consequence what expectations to hold. As economic decisions are conditioned on expectations holding proper or rational expectations eliminates the possibility of ex ante inefficiencies. The choice of expectation formation technology is not trivial as the paper assumes that information gathering and processing are costly. Consequently, economic agents must make informed decisions with the regard to the quality of expectation formation technologies they wish to use. The paper shows that agents' optimization over expectations not only adds on to realism, but also can carry non trivial implications for the behavior of macroeconomic variables. Specifically, the paper illustrates that endogenous expectation revisions can be a source of permanent oscillations in aggregate demand and can prevent an economy from settling into a steady state. In addition, the paper quantifies intangible notions such as overheating, overborrowing, and output gap. Finally, the paper shows that active policy measures can limit inefficiencies resulting from output fluctuations.

JEL Classification Numbers: D84, E32.

Key Words: Business Cycles, Expectation Formation, Costly Information Acquisition.
\end{abstract}

\section{Introduction}

Short run oscillatory movements in macroeconomic variables are a distinctive characteristic of modern economies. Accordingly, the phenomenon has been central to macroeconomic analysis. The paper contributes to the extensive existing literature and presents a complementary rationalization for the occurrence of

*Please send comments to mkdudek@sgh.waw.pl. 
recession and expansions. The paper offers a novel approach. It builds on a recent contribution of Brock and Hommes [7] and argues that expectations can be a key determinant of short run macroeconomic performance. Specifically, it shows, in a general equilibrium framework, that rational selection of different expectation formation technologies can be a source of endogenous fluctuations in aggregate demand.

The stark coexistence of recessions and expansions has attracted a considerable attention from the profession. Historically economists have attempted to account for business cycles by interpreting them as combinations of deterministic cycles of different lengths. However, efforts to represent fluctuations in aggregate output as the outcome of regular Kitchin (3-year), Juglar (10-year), Kuznets (20-year), and Kondratiev (50-year) cycles have been abandoned in favor of approaches that emphasize either the importance of stochastic disturbances, or the interaction of expectations and multiple equilibria, or assign the key responsibility to intrinsic nonlinearities of macroeconomic systems.

The real business cycle literature based on stochastic dynamic equilibrium models and spurred by the initial contribution of Kydland and Prescott [39] defines the main stream approach towards understanding short run fluctuation. The approach relies on general equilibrium modelling and identifies exogenous technology, taste or government purchases shocks as the driving forces of business cycles. The approach has proven to be relatively successful in accounting for qualitative and quantitative aspects of business cycles. This paper shares with the main stream general equilibrium approach. However, the results its presents add on to the existing literature. Specifically, the paper shows that cycles need not imply, even in the absence of nominal rigidities, movements in the potential level of output.

The second approach, most notable examples being Diamond [15], Kiyotaki [29], exploits the fact that a priori economic systems need not have unique equilibria and, therefore, downturns and upswings in economic activity can be an outcome of movements between different equilibria. The approach despite its theoretical appeal requires several tacit assumptions with the need for the existence of exogenous coordinating device being a key shortcoming. Moreover, voluntary coordination by rational and high payoff seeking economic agents on an inferior equilibrium implies that fluctuations and resulting welfare losses are largely self-inflicted and most importantly totally avoidable.

The contributions in the third group, Grandmont [22], Aghion, Banerjee and Piketty [2], Matsuyama [32], [33] note that the cyclicality in macroeconomic variables can be an inherent property of macroeconomic systems and fluctuations can in fact be endogenous. This paper falls into this final category, i.e., it argues that high frequency dynamics in macroeconomic variables can be endogenous. However, unlike other contributions it illustrates that equilibrium actions of rational and high payoff seeking economic agents rather than intrinsic properties of the underlying equilibrium equations can induce fluctuations in systems that are otherwise stable.

The paper develops a general equilibrium model based on the OLG model of Diamond [14] and the monopolistic competition model of Blanchard and Kiy- 
otaki [5]. The presence of monopolistic competition allows the composition of aggregate demand aside from fundamentals: preferences, technology, and resources affect aggregate output. The composition of aggregate demand depends amongst other factors on the perception of the future. In particular, an expectation of high income flows in the future results, due to intertemporal smoothing, in low savings today. Low savings imply high consumption, which leads to high output. Conversely, an expectation of low income streams in the future provides an incentive to increase savings. Increased savings curtail consumption and result in low output. Consequently, changes in expectations lead to fluctuations in aggregate output. Expectations, however, are not assumed to be exogenous. Quite the contrary expectations and foremost the process of their formation are endogenized and any changes in expectations constitute an equilibrium outcome.

The paper follows the methodology of Brock and Hommes [7] and endogenizes expectation formation in an environment in which it is costly to collect and process information. Specifically, the paper assumes that economic agents need to expend resources if they wish to obtain reliable assessments of the future values of macroeconomic variables. In particular, naive assessments, based on past realizations and past experience, are assumed to be costless. On the other hand perfect foresight assessment can be obtained only at a cost. Naturally, expectations based on naive assessments allow economic agents to save on the information gathering and processing costs, but lead to mistakes along the intertemporal margin and result in a loss in terms of utility as the consumption profile is not smoothened out optimally. Similarly, expectations formed on the basis of reliable assessments eliminate the possibility of errors along the intertemporal margin and do not impose direct losses in terms of utility, but can be formed provided that the proper information gathering and processing costs have been accrued. Naturally, rational agents need to balance the two effects in equilibrium and make an informed decision with regard to the type of expectations they wish to hold.

The paper shows that the desire of economic agents to economize on information gathering and processing costs can prevent an economy from settling into a steady state. The paper develops a model in which the economy follows and unstable dynamic equation when all economic agents choose to form expectations in an adaptive manner and follows a dynamic equation that settles into a rest point if economic agents choose to form expectations in a rational (perfect foresight) manner. Therefore, adaptive or naive learning, expectations based on past experience, puts the economy on explosive trajectories and ultimately must result in significant errors along the intertemporal margin and a substantial loss in terms of utility. Economic agents in the face of significant errors along the intertemporal margin expend resources and shift toward rational assessments of the future. This puts the economy on a convergent path. However, the economy never converges towards a steady state. Convergence implies by definition that future outcomes resemble current outcomes, therefore, were convergence to occur passive or adaptive learning would lead to minuscule errors along the intertemporal margin. Consequently economic agents would find it optimal to switch toward adaptive learning. This, however, would lead to divergence and 
the cycle would repeat itself resulting in permanent oscillations even in the absence of exogenous innovations. Oscillations are not a consequence of mathematical properties of underlying dynamic equilibrium equations. The path that the economy follows is chosen in equilibrium and a priori the economy need not follow an oscillatory path.

Economic theory either perceives downturns in economic activity as shifts in the potential level of output or as temporary deviations from the underlying level of potential level of output. This paper falls into the latter category and illustrates that endogenous revisions of expectations cause output to fluctuate around the trend. Specifically, the paper shows that overly optimistic expectations lead to high consumption and to high output and pessimistic expectations cause consumption to be low and output to fall below the potential level of output. Moreover, the paper illustrates that a boom caused by consumer confidence and consumer spending can endogenously end with a drastic revision of expectations and a cut in the level of consumption. The paper, thus, rationalizes consumption shocks thought to be at the root of the 1990/91, see Blanchard [4], and 2001 recessions. Moreover, the paper formalizes and gives precise meaning and clear interpretation to intangible notions such as: overheating, output gap, overborrowing, or irrational spending sprees etc. Consequently, the paper shows that consumer behavior can depart from optimal first best spending plans and that the deviations can become costly ex post and can lead to endogenous revisions of expectation. Finally, the paper provides a justification for the usage of countercyclical policy measures allowing for smoothing out deviations from the trend.

The paper resembles most closely the recent contribution by Brock and Hommes [7] who study the dynamics of a cobweb model with costly formation of expectations, showing that agents may find it optimal to switch between different expectation formation technologies if it is costly to collect data. This paper, contrary to Brock and Hommes, allows agents to choose the optimal expectation formation technology in the rational fashion based on the level of utility that it gives, whereas in Brock and Hommes [7] agents choose expectation formation technologies based on their past performance. Moreover, in this setting we allow agents to switch expectation formation technologies at any point in time and all agents do indeed use the optimal one. In Brock and Hommes[7], on the other hand, some agents are artificially constrained to use suboptimal expectation formation technologies.

Ramey and Evans [18] also present a model that is similar to the one in this paper. Their model allows to trade between accuracy an income, a feature exploited in this paper, However, the dynamics in their model are driven by changing environment. In this paper the changes of environment are endogenous, not triggered by exogenous movements in states of the world, and are solely due to changes in the behavior of economic agents.

Blanchard [6] studies a model in which agents learn about the economy. He finds that learning need not lead to a full revelation of the fundamentals of the economy and that in the limit agents may not know the correct model of the economy. This paper presents a complementary result. It is shown 
that learning from past experience allows to fully identify the structure of the economy. However, the paper illustrates that the structure of the economy is itself affected by the learning process and hence any inferences based on past data if used in decision making process affect the structure of the economy. In other words, the paper presents an example of the Lucas Critique [31] in the context learning and expectation formation affecting the structure of the economy. Furthermore, it is shown that learning may under some parameter values cause instability in systems that otherwise would tend to a steady state equilibrium a point initially brought by Evans [16], Marcet and Sargent [34] in a partial equilibrium context.

The recent contribution of Reis [41] shares many of the findings of this paper. Specifically, the paper, as in Reis [41], shows that informational costs imply that consumption profiles depart from the optimal first best. However, Reis's analysis in a partial equilibrium one and focuses on consumer behavior in the context exogenously changing environment and costly information acquisition. This paper is cast in a general equilibrium framework and shows that updates of consumption plans can lead to endogenous changes in the environment and to endogenous oscillations.

The paper is organized in six sections. Section (2) outlines the underlying model. Section (3) determines the equilibrium. Section (4) endogenizes the process of expectation formation and presents sample dynamics. Section (5) focuses on policy considerations. Finally, section (6) concludes.

\section{M odel}

There are three main components of the model. The intertemporal aspects are captured in the framework of the Diamond [14] OLG model. In addition, Blanchard and Kiyotaki [5] imperfect competition framework allows shifts in the composition of aggregate demand to influence contemporaneous variables. Finally, Brock and Hommes [7] approach is used to endogenize expectation formation. The model is fully analytically tractable.

\subsection{A gents}

There are a continuum of measure one of agents born each period. Each agent lives for two periods and is endowed with a unit of labor in the first period of her life. An agent born at time $t$ values consumption in the first period of her life, when she is young, and consumption in the second period of her lifer, when she is old. The preferences of an agent born at time $t$ are represented by the following utility function

$$
U\left(c_{1, t}, c_{2, t+1}\right)=\log \left(c_{1, t}\right)+\log \left(c_{2, t+1}\right) .
$$

The logarithmic utility simplifies the intertemporal problem immensely and is chosen for analytic convenience. 


\subsection{Goods}

There are two classes of final goods in this economy and a class of intermediate goods. There is a single final consumption good. There are a continuum of measure one of intermediate goods, which are used as inputs in the production process of the final consumption good. In addition, there is physical capital, which plays both the role of an investment good, used as a form of saving, and of a productive input.

\subsection{Production}

The final consumption good is produced from intermediate goods via the following CES production function

$$
c_{t}=\left(\int_{0}^{1} c_{i, t}^{\gamma} d i\right)^{\frac{1}{\gamma}}
$$

where $c_{i, t}$ denotes the input of the intermediate good $i$. The market for the consumption good is perfectly competitive.

The intermediate goods are produced using a Cobb-Douglas technology

$$
c_{i, t}=k_{i, t}^{\alpha} l_{i, t}^{1-\alpha},
$$

where $k_{i, t}$ denotes the amount of capital and $l_{i, t}$ denotes the amount of labor used in the process of production of good $i$. The markets for the intermediate goods are monopolistic. The demand for good $i$ takes the form

$$
p_{t}^{i}=D_{t}^{1-\gamma} p_{t}^{\gamma} c_{i, t}^{\gamma-1}
$$

where $D_{t}$ denotes the level of demand for the final consumption good and $p_{t}^{i}$ and $p_{t}$ denote the price of the intermediate good $i$ and the consumption good, respectively.

Physical capital is produced using a linear technology

$$
Q_{k}=l_{t}^{k},
$$

out of labor, where $l_{t}^{k}$ denotes the amount of labor used in the production of physical capital. In addition, it is assumed that the market for physical capital is perfectly competitive. ${ }^{1}$

The input output matrix is presented in figure (1.)

\subsection{Income}

There are several sources of income in this economy. First of all, factors of production receive rental fees. Secondly, imperfect competition in the intermediate goods sectors allows profits to arise in equilibrium. It assumed that

\footnotetext{
${ }^{1}$ The fact that labor is the only input in the production of physical capital allows for a complete analytic tractability of the model. However, the results do not depend on this specific assumption.
} 


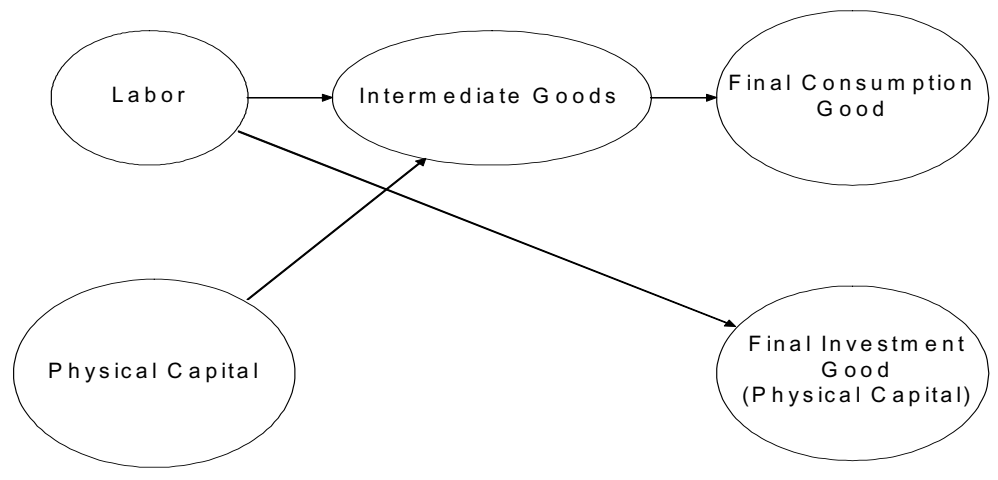

Figure 1: Input-Output Matrix

profits that arise in equilibrium belong to the old. Moreover, it is assumed that in equilibrium there is no trade in profit shares.

The income of young agents comes from labor supply and is equal to the wage income, given by,

$$
y_{1, t}=w_{t} .
$$

The income of old agents comes from three sources. Recall that savings take the form of physical capital. Therefore, old agents can sell the capital stock that they own, the capital stock they acquired the period before net of depreciation. In addition, they can rent out their capital and receive the return on it. Finally, old agents receive equilibrium profits. The income of the old is given by,

$$
y_{2, t}=(1-\delta) p_{t}^{k} k_{t}+r_{t} k_{t}+\pi_{t},
$$

where $p_{t}^{k}$ denotes the equilibrium price of a unit of physical capital, $\delta$ the rate of depreciation of physical capital, $r_{t}$ the rental costs, and $\pi_{t}$ denotes the equilibrium profits.

\section{Equilibrium}

The equilibrium involves several aspects. There are standard intratemporal and intertemporal considerations of the consumer problem and the producer problem. In addition, equilibrium comprises the process of selection expectation formation technology. 


\subsection{Consumer Problem}

Consumers live for two periods. Young agents face a standard intertemporal choice problem, i.e., young agents must decide how to allocate their life time earnings between the two periods. Therefore, they maximize their utility

$$
U\left(c_{1, t}, c_{2, t+1}\right)=\log \left(c_{1, t}\right)+\log \left(c_{2, t+1}\right)
$$

subject to the budget constraints

$$
\begin{aligned}
p_{t} c_{1, t}+s_{t} & =y 1, t \\
s_{t} & =p_{t}^{k} k_{t+1} \\
p_{t+1} c_{2, t+1} & =r_{t+1} k_{t+1}+(1-\delta) p_{t+1}^{k} k_{t+1}+\pi_{t+1}
\end{aligned}
$$

where $p_{t}$, and $p_{t+1}$ denote the prices of the consumption good in period $t$ and period $t+1$, respectively, $p_{t}^{k}$ and $p_{t+1}^{k}$ are the prices of physical capital in the two periods, and $s_{t}$ denotes the amount saved in period $t$. Physical capital is the only investment good hence in equilibrium the amount saved must be equal to the purchases of physical capital, i.e., it must be $p_{t}^{k} k_{t+1}=s_{t}$.

The calculations pertaining to the intertemporal considerations in this model are by far more demanding than those in the original Diamond model. Therefore, in order to simplify the exposition, to avoid a discussion on potential corner solutions, the rate of depreciation of physical capital is assumed to be one, i.e., from now on it is assumed that $\delta=1$. The last assumption implies that physical capital once purchased can only be rented out and cannot be resold.

Optimality along the intertemporal margin requires that

$$
s_{t}=\frac{1}{2}\left(y_{1, t}-\frac{p_{t}^{k} \pi_{t+1}}{r_{t+1}}\right) .
$$

Therefore, the capital stock in the economy evolves according to the following dynamic equation

$$
k_{t+1}=\frac{1}{2}\left(\frac{y_{1, t}}{p_{t}^{k}}-\frac{\pi_{t+1}}{r_{t+1}}\right) .
$$

\subsection{Intratemporal Allocation}

Let $k_{t}$ denote the capital stock available in period $t$ (savings of the young in period $t-1$.) Moreover, let $D_{t}$ denote the demand for the final consumption good at time $t$ and let $D_{t}^{k}$ be the demand for the investment good, i.e., the amount saved at time $t$. Finally, let $\beta_{t}$ be the fraction of income saved at time $t$.

The market for the investment good is perfectly competitive and the production function for the investment good is linear hence the price of a unit of physical capital is equal to the marginal cost, i.e., to the wage $p_{t}^{k}=w_{t}$. Recall that the income of the young is equal to the wage and that the savings take 
the form of physical capital. Therefore, the level of investment, newly installed capital, at time $t$ is given by

$$
k_{t+1}=\beta_{t} .
$$

Moreover, the form of the production function implies that the level employment in the investment good sector by $l_{t}^{k}$ is given by $l_{t}^{k}=\beta_{t}$. The market clearing condition implies that the level of employment in the intermediate good sectors is given by

$$
l_{t}^{i n t}=1-\beta_{t} .
$$

The market for the final consumption good is perfectly competitive. The production function is of a standard CES form. Therefore, the price of a unit of the final consumption good is equal to the marginal costs and is given by

$$
p_{t}=\left(\int_{0}^{1} p_{i}^{\frac{\gamma}{\gamma-1}} d i\right)^{\frac{\gamma-1}{\gamma}},
$$

where $p_{i}$ denotes the price of intermediate good $i$. Markets for intermediate goods are monopolistic. The demand for a given good is given by equation 4 . The price of intermediate good $i$, note assumption of a CES production function, is equal to a markup over marginal costs

$$
p_{i}=\frac{1}{\gamma} \frac{1}{\alpha^{\alpha}} \frac{1}{(1-\alpha)^{1-\alpha}} r^{\alpha} w^{1-\alpha} .
$$

Monopolistic competition in the intermediate goods sectors together with the assumption of the CES production function allow to establish that the level of profits generated in the economy is given by

$$
\pi_{t}=(1-\gamma) D_{t},
$$

and the total wage bill in the intermediate goods sectors assumes the form

$$
w_{t} l_{t}^{\text {int }}=(1-\alpha) \gamma D_{t},
$$

and the factor payment to physical capital can be expressed ad

$$
r_{t} k_{t}^{i n t}=\alpha \gamma D_{t} .
$$

Note that in equilibrium the level of physical capital engagement in the intermediate goods sector $k_{t}^{i n t}$ is equal to the supply of capital $k_{t}$, recall that only labor is used in the process of production of the investment good (physical capital), whereas the level of employment in the intermediate goods sectors $l_{t}^{\text {int }}$ is given by equation (11). Furthermore, it is straightforward to establish that

$$
\begin{gathered}
\frac{\pi_{t}}{r_{t}}=\frac{1-\gamma}{\alpha \gamma} k_{t}, \\
\frac{r_{t}}{w_{t}}=\frac{\alpha}{1-\alpha} \frac{l_{t}^{i n t}}{k_{t}} .
\end{gathered}
$$


Finally, combining the above relationships it is possible to show that the equilibrium level of the price of the final consumption good is given by

$$
p_{t}=\frac{1}{1-\phi}\left(\frac{l_{t}^{i n t}}{k_{t}}\right)^{\alpha} w_{t},
$$

where $\phi=(1-\gamma(1-\alpha))$.

It is natural to define the level of output in this model as the sum of incomes of young and old agents, i.e.,

$$
G D P_{t}=y_{1, t}+y_{2, t} .
$$

The income of the young is simply equal to the wage, $y_{1, t}=w_{t}$, and the income of the old comes from two sources: earnings received from physical capital rental and profits, i.e., $y_{2, t}=r_{t} k_{t}+\pi_{t}$. Moreover, the demand for the consumption good comes from two sources: the old devote all of their wealth towards purchases of the consumption good and the young devote a fraction $1-\beta_{t}$ of their income towards consumption, hence

$$
D_{t}=y_{2, t}+\left(1-\beta_{t}\right) y_{1, t} .
$$

Therefore, the level of output is given by

$$
G D P_{t}=\frac{1-\phi \beta_{t}}{1-\phi} w_{t} .
$$

Finally, the level of output expressed in terms of the price of the consumption good is given by

$$
y_{t}=\frac{\left(1-\phi \beta_{t}\right)}{\left(1-\beta_{t}\right)^{\alpha}} k_{t}^{\alpha},
$$

for completeness recall that the employment in the intermediate goods sectors equals $l_{t}^{\text {int }}=1-\beta_{t}$.

Equation (21) completes the description of the intratemporal equilibrium. Moreover, the last equation illustrates that the aggregate output not only depends on the supply side characteristics, i.e., the technology and the resources available, the amount of physical capital $k_{t}$, but also on the marginal propensity to save $\beta_{t}$. In other words, not only the supply side determines output, but also the composition of aggregate demand influences the aggregate output. The last finding stems from fact that the sectors of intermediate goods are monopolistically competitive whereas the investment good sector is perfectly competitive. Such a structure leads to the existence of aggregate demand externality, which in turn influences aggregate variables. Young agents by changing the amount of income saved, affect the demand for the consumption good. However, by affecting the demand they affect profits in the intermediate goods sectors. A change in the profits in the intermediate goods sectors affects the income of the old agents, which in turn affects the demand for the consumption good, which 
again affects the profitability, and so on. This process continues and results in an equilibrium change in the aggregate output. ${ }^{2}$

\subsection{Intertemporal Allocation}

The ultimate goal of this paper is to show that macroeconomic cycles can constitute an equilibrium outcome. It is widely known, Grandmont [20], that the Diamond OLG model, used as the benchmark in this paper, itself is capable of generating endogenous cycles. Therefore, it is imperative to show that the existence of cycles in the model presented in the paper is due to expectation selection rather than being due to the fact that the Diamond OLG model is a key building block of the model. Accordingly, the paper assumes first perfect foresight and shows that the economy does not exhibit endogenous fluctuations and then assumes that information gathering and processing are costly and solves for the equilibrium allowing agents to select amongst different expectation formation technologies.

Let $x_{t+1}$ denote the present value of future profit income, i.e., let

$$
x_{t+1}=\frac{\pi_{t+1}}{r_{t+1}} .
$$

The equilibrium outcomes in period $t$ not only depend on the values of macroeconomic variables in period $t$, but also depend on values of variables in period $t+1$. In particular, the amount saved at time $t$, as equation (9) indicates, depends on $x_{t+1}$. Therefore, the value of capital stock in period $t+1$, which is itself determined in period $t$, depends on the way economic agents form expectations at time $t$ regarding the value of $x_{t+1}$. Thus, agents' expectations at time $t$ regarding period $t+1$ influence economic activity in period $t$.

Let $\Omega_{t}$ be the information set of a young agent born at time. Her problem given the information set $\Omega_{t}$ is to maximize

$$
U\left(c_{1, t}, c_{2, t+1}\right)=\log \left(c_{1, t}\right)+E_{t}\left(\log \left(c_{2, t+1}\right) \mid \Omega_{t}\right)
$$

subject to her budget constraints. Under the assumption of perfect foresight the information set $\Omega_{t}$ contains the values of all current and future variables, in particular, the information set at time $t$ contains the value of $x_{t+1}$, i.e.,

$$
x_{t+1} \in \Omega_{t}
$$

Therefore, young agents at time $t$ are fully aware of the precise value of $x_{t+1}$ and accordingly the amount that they save is equal to, see equation (9),

$$
k_{t+1}=\frac{1}{2}\left(1-x_{t+1}\right) \text {. }
$$

\footnotetext{
${ }^{2}$ The fact that the production functions in the final consumption good sector and the investment good sector differ additionally contributes this result.
} 


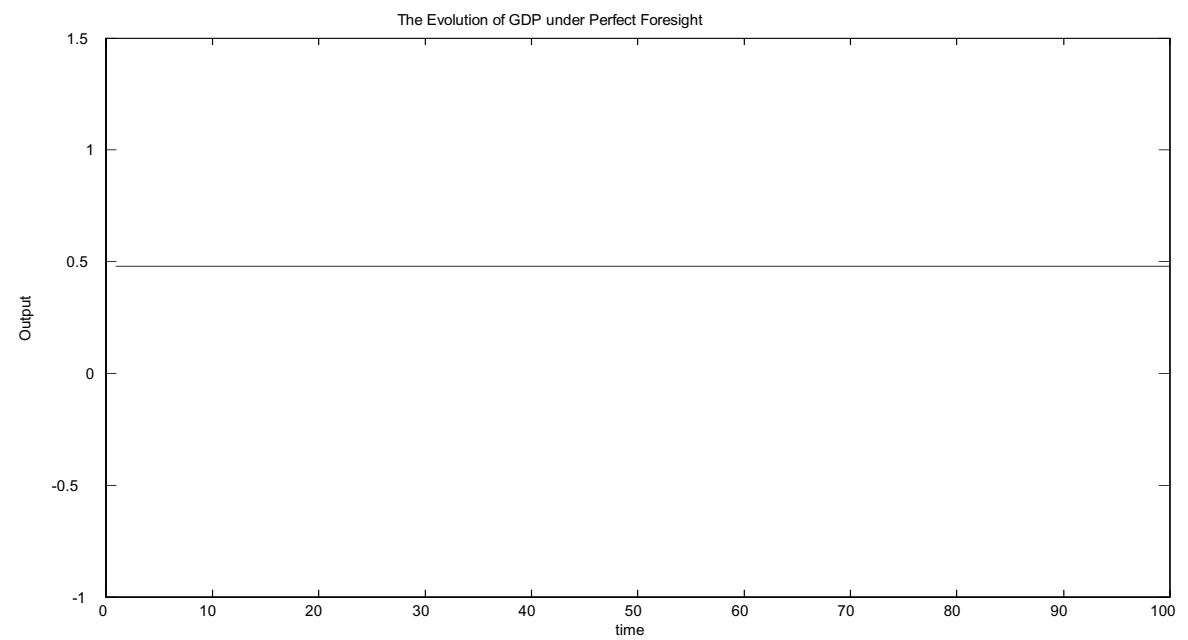

Figure 2: The Evolution of Ouptuput under Perfect Foresight.

Furthermore, equation (17) indicates that $x_{t}=2 \psi k_{t}$, where $\psi=\frac{1-\gamma}{\alpha \gamma}$. Iteration by one period implies that $x_{t+1}=2 \psi k_{t+1}$. Thus, the level of investment at time $t$ is given by

$$
k_{t+1}=\frac{1}{2(1+\psi)} \text {. }
$$

Therefore, $\forall t_{1}, t_{2}: k_{t_{1}}=k_{t_{2}}$. Naturally, under the assumption of perfect foresight the level of investment and the level of physical capital are constant and independent of time. Moreover, recall that in equilibrium the marginal propensity to save equals to the level of investment equation (10.) Therefore, it turns out that in equilibrium the average propensity to save is a constant, i.e., $\forall t_{1}, t_{2}: \beta_{t_{1}}=\beta_{t_{2}}$. Consequently aggregate output, as given by formula (21), is constant. Figure (2) presents sample dynamics of output.

Clearly, the assumption of perfect foresight leads to a stable equilibrium in which all variables are constant and, in particular, in which aggregate output does not fluctuate. Therefore, should there any oscillations occur if the assumption of perfect foresight is relaxed the oscillations will not be due to the fact that the Diamond OLG model is used as the benchmark.

The assumption of perfect foresight leads to an uninteresting equilibrium dynamics. The situation is different if one allows for alternative expectation formation technologies. Recall that $x_{t+1}$ determines the amount saved by young agents at time $t$. Therefore, economic agents must form expectations with the regard to $x_{t+1}$. In particular, if agents decide to expect $x_{t+1}^{e}$ at time $t$ then the level of investment and, hence, the marginal propensity to save take the form

$$
\beta_{t}=k_{t+1}=\frac{1}{2}\left(1-x_{t+1}^{e}\right) .
$$


Observe that the intratemporal problem is unaffected by the characteristics of the expectation formation technology, therefore, the equilibrium level of output, measured in terms of the price of the consumption good, at time $t$ is still given by

$$
y_{t}=\frac{\left(1-\phi \beta_{t}\right)}{\left(1-\beta_{t}\right)^{\alpha}} k_{t}^{\alpha},
$$

where $\beta_{t}$ is given by (24). Also recall that in equilibrium $k_{t}=\beta_{t-1}$. Note that in this case output need not be constant. Any change in $x_{t+1}^{e}$ leads to a move of $\beta_{t}$ and consequently affects the level of output. Therefore, if in equilibrium economic agents choose to modify their expectations the change will result in an innovation in the level of output.

In summary expectations affect aggregate activity because they affect the marginal propensity to save. Optimism leads economic agents to devote a smaller fraction of their incomes toward savings and in turn to high output. Conversely, pessimistic expectations cause economic agents to save a higher fraction of their incomes, which leads to low demand for consumption good and in turn to low output.

\section{Optimal Expectation Formation}

An ability to predict the future with certainty presents economic value as it allows for optimal behavior along the intertemporal margin. However, normally, economic agents do not have enough capacity to formulate correct point estimates of future economic variables. In reality, economic decision making relies only on imperfect, second best, assessments of future outcomes. Specifically, economic agents at any point in time decide which or what combination of forecasting tools to develop and to rely on. Similarly, economic agents decide what information sets to base their decisions on. The mainstream of the literature either assumes that information regarding future variables arrives exogenously and economic agents use that information to improve their assessments of the future, or it assumes that agents willing to sharpen their assessments of the future need to purchase informative signals at some costs. This paper follows the latter approach and assumes that economic agents incur a cost in the form of utility when they attempt to enhance their estimation of the future.

\subsection{Rational Selection of an Expectation Formation Tech- nology}

The intertemporal problem of an agent at time $t$ involves an assessment of $x_{t+1}$. Therefore, a particular assessment leads to a particular behavior along the intertemporal margin. The paper develops a framework in which agents are allowed decide on the quality of assessments of relevant future variables. In other words, the paper refrains from imposing any specific expectations formation technology. On the contrary, it treats the process of expectation formation as a 
part of equilibrium and allows agents to decide what expectations to hold with regard to given variables.

Observe that there are no stochastic disturbances in the model. All outcomes are purely deterministic. However, economic agents need not have the ability or desire to discriminate between deterministic and stochastic dynamics. Accordingly, it is assumed that economic agents treat observed values as being realizations of some underling random variables. Specifically, economic agents consider realizations of $x_{t}$ as random draws from some distribution. The distribution can be conditional on past realized values and can assumes an extreme form of the delta (Dirac) function.

Recall that the level of utility of a representative agent can be expressed as

$$
U\left(c_{1, t}, c_{2, t+1}\right)=\log \left(\frac{w_{t}-s_{t}}{p_{t}}\right)+\log \left(\frac{r_{t+1} \frac{s_{t}}{p_{t}^{k}}+\pi_{t+1}}{p_{t+1}}\right) .
$$

Note that under the assumption of logarithmic utility the real value of future profits $x_{t+1}=\frac{\pi_{t+1}}{r_{t+1}}$ is the only, even in the presence of uncertainty, future variable relevant for the determination of the level of savings. Naturally, apart from $x_{t+1}$ both future rental price of capital $r_{t+1}$ and the future price of consumption $p_{t+1}$ influence the level of realized utility. However, beliefs pertaining to variables $p_{t+1}$ and $r_{t+1}$ do not affect the intertemporal problem . Therefore, the paper focuses solely on expectation formation with respect to variable $x_{t+1}$.

Let $F_{x_{t+1}}^{t}$ be the prior distribution of $x_{t+1}$ at time $t$. In addition, let $E_{t} x_{t+1}$ be the expected value of $x_{t+1}$ at time $t$ and let $\sigma_{x_{t+1}}^{2}$ be the corresponding variance. In the literature there are two mainstream approaches normally followed in the context of decision making under uncertainty. Expected utility maximization is the dominant one while certainty equivalence approach remains a tool of convenience. This paper follows the latter approach, i.e., it is assumed that economic agents treat random variables as if they were equal to their means. This simplification allows for a complete analytic tractability of the model. The results are qualitatively unchanged. However, with a certainty equivalence approach an important channel is absent. There is no precautionary saving motive, which when present enriches the equilibrium dynamics.

At any point in time economic agents need an assessment of $x_{t+1}$ to decide on the level of savings. It is assumed that the prior $F_{x_{t+1}}^{t}$ is available to economic agents free of any costs. However, economic agents are not constrained to this specific piece information. In addition, each agent can purchase a signal of the true value of a given future variable. Specifically, signals are assumed to be of the following form

$$
\nu_{x_{t+1}}=\left\{\begin{array}{c}
x_{t+1} \text { with probability } q \\
\sim F_{x_{t+1}} \text { with probability } 1-q,
\end{array}\right.
$$

where $F_{x_{t+1}}$ denotes the prior distribution of variable $x_{t+1}$. In other words, it is assumed that with a chance $q$ the signal reveals the true value of the variable and with a chance $1-q$ the signal gives a random draw from the 
prior distribution, i.e., is completely uninformative. Naturally, the larger the value of $q$ the more informative a given signal is. The paper assumes that the degree of informativeness of a given signal $q$ is a choice variable. Agents are free to choose how well informed they become. However, a given choice of $q$ is accompanied with a cost in terms of utility $C\left(q^{2}\right)$. The cost function satisfies standard properties

$$
C(0)=0, C^{\prime}\left(q^{2}\right) \geq 0 \text { and } C^{\prime \prime}\left(q^{2}\right) \geq 0 .
$$

Note that agents can choose to be fully informed. They select $q$ to be equal to one. However, if they do so they must pay the cost $C(1)$. On the other hand, agents can rely only on their priors, i.e., they can set $q$ to be equal to zero and save on information acquisition as $C(0)=0$.

An agent who decides at time $t$ to purchase a signal of quality $q_{t}$ receives a signal $\nu$ and then forms the corresponding posterior distribution. Specifically, if she receives a signal $\nu_{x_{t+1}}$ for variable $x_{t+1}$ then the corresponding posterior distributions is obtained using the Bayes rule and is given by $F_{x_{t+1}}\left(x_{t+1} \mid \nu_{x_{t+1}}\right)$. In the following step the posterior distributions are used in the process of the determination of optimal behavior.

Recall that under the assumption of perfect foresight the optimal level of investment is given by

$$
k_{t+1}=\frac{1}{2}\left(1-x_{t+1}\right)
$$

and is independent of the future consumption price $p_{t+1}$ and the future rental costs $r_{t+1}$. Moreover, given the assumption of logarithmic utility the two variables remain irrelevant even in the case of uncertainty and expected utility maximization approach. In order to preserve complete analytic tractability the paper deals with uncertainty by assuming certainty equivalence behavior or more precisely by assuming that economic agents treat future variables as if they were equal to their means. Under this assumption the level of investment is given by

$$
k_{t+1}=\frac{1}{2}\left(1-E\left(x_{t+1} \mid \nu_{x_{t+1}}\right)\right) \text {. }
$$

This form of behavior implies that realized utility conditional on signal $\nu_{x_{t+1}}$ is given by

$$
U=A_{t}+\log \left(\left(1+x_{t+1}\right)^{2}-\left(x_{t+1}-E\left(x_{t+1} \mid \nu_{x_{t+1}}\right)\right)^{2}\right)
$$

where $A_{t}=-\log p_{t}+\log \left(w_{t}\right)+\log \left(p_{t}^{k}\right)+\log \left(\frac{r_{t+1}}{p_{t+1}}\right)-2 \log (2)$. Note that the level of realized utility depends both on the future price of consumption $p_{t+1}$ and on future rental cost $r_{t+1}$. Of course it also depends on the realized value of $x_{t+1}$. Clearly, as long as the true realized value differs from the expected one economic agents pay a cost in the form of

$$
\varepsilon^{2}=\left(x_{t+1}-E\left(x_{t+1} \mid \nu_{x_{t+1}}\right)\right)^{2}
$$

as the consumption profile is not smoothened out optimally. Note that a priori economic agents can avoid this cost by purchasing a perfectly informative signal. 
It is apparent that the realized utility depends on two factors. First of all, it depends on the state of nature, i.e., the true values of $x_{t+1}, p_{t+1}$ and $r_{t+1}$ and on $\nu_{x_{t+1}}$ a particular signal received for $x_{t+1}$. However, when an agent decides to purchase a signal she neither knows what signal she will receive nor she knows the true state of nature. Nevertheless, she must decide on the quality of a signal she wishes to receive before any uncertainty is resolved. Observe that conditional on a given state of nature $x_{t+1}$ the loss $\varepsilon^{2}$ resulting from insufficient consumption smoothing is a function of a specific signal drawn $\nu_{x_{t+1}}$. Moreover, both the signal and the resulting loss are unknown ex ante. Consequently economic agents must form expectations with the regard of the potential loss $\varepsilon^{2}$. Let $G\left(\nu_{x_{t+1}} \mid x_{t+1}\right)$ be the conditional, also obtained by Bayes rule, distribution function of a given value of a signal given that the state of nature is $x_{t+1}$. Then the "expected" level of realized utility, again performing for analytic convenience certainty equivalence calculation, conditional on a given state of nature $x_{t+1}$ is given by

$$
U=A_{t}+\log \left(\left(1+x_{t+1}\right)^{2}-\int\left(x_{t+1}-E\left(x_{t+1} \mid \nu_{x_{t+1}}\right)\right)^{2} d G\left(\nu_{x_{t+1}} \mid x_{t+1}\right)\right) .
$$

Observe that the level of realized utility depends on the true state of nature $x_{t+1}$ and on the expected error resulting from suboptimal consumption smoothing. Naturally, different realizations of $x_{t+1}$ will lead to different levels of realized utility. Unfortunately, the value of $x_{t+1}$ is also ex ante unknown, therefore, the unconditional "expected" realized utility can only be obtained by using the underlying priors. A certainty equivalence evaluation leads to

$$
U=A_{t}+\log \left(E_{t}\left(1+x_{t+1}\right)^{2}-\int V\left(x_{t+1} \mid \nu_{x_{t+1}}\right) d G\left(\nu_{x_{t+1}}\right)\right),
$$

where $G(-)$ denotes the unconditional distribution of $\nu_{x_{t+1}}$ and the prior $F_{x_{t+1}}$ is used to determine $E_{t}\left(1+x_{t+1}\right)^{2}$.

The specific form of the distribution of signals (26) implies that the conditional expected value of $x_{t+1}$ can be expressed as

$$
E\left(x_{t+1} \mid \nu_{x_{t+1}}\right)=q_{t} \nu_{x_{t+1}}+\left(1-q_{t}\right) E_{t} x_{t+1}
$$

and the conditional variance takes the form

$$
V\left(x_{t+1} \mid \nu_{x_{t+1}}\right)=q_{t}\left(1-q_{t}\right)\left(\nu_{x_{t+1}}-E_{t} x_{t+1}\right)^{2}+\left(1-q_{t}\right) \sigma_{x_{t+1}}^{2} .
$$

Therefore, the realized utility under the assumption of certainty equivalence behavior before a specific signal of quality $q_{t}$ is purchased is given by

$$
U=A_{t}+\log \left(E_{t}\left(1+x_{t+1}\right)^{2}-\left(1-q_{t}^{2}\right) \sigma_{x_{t+1}}^{2}\right) .
$$

Naturally, the more informative a given signal is the higher the "expected" realized utility. Similarly, the larger the ex ante uncertainty the smaller the "expected" realized utility. Recall that signals can be obtained only at some 
cost. Specifically, a signal of quality $q_{t}$ carries a cost in terms of utility of $C\left(q_{t}^{2}\right)$. Therefore, the ex ante level of utility net of information acquisition costs is given by

$$
U=A_{t}+\log \left(E_{t}\left(1+x_{t+1}\right)^{2}-\left(1-q_{t}^{2}\right) \sigma_{x_{t+1}}^{2}\right)-C\left(q_{t}^{2}\right) .
$$

Economic agents given their priors must decide on the quality of signals they receive. Technically, economic agents must balance the loss in terms of utility resulting from insufficient consumption smoothing with the loss in terms of utility resulting from information purchase, i.e., they select the quality $q_{t}$ so as to the level of utility is the largest. The first order condition for an interior solution is given by

$$
\frac{\left(1+E_{t} x_{t+1}\right)^{2}}{\sigma_{x_{t+1}}^{2}}=\frac{1}{C^{\prime}\left(q_{t}^{2}\right)}-q_{t}^{2} .
$$

The right hand side is monotone decreasing in $q_{t}^{2}$. The left hand side depends on the ratio of the life time expected income to its variability. The solution is characterized by several intuitive features. First of all, the higher the underlying uncertainty the larger the precision of signals purchased. Similarly, if the underlying uncertainty is low then only very uninformative signals are purchased and expectations are backward looking. Moreover, the higher the expected value of $x_{t+1}$ the lower the precision of signals. This is due to the fact that with concave utility a loss in terms of utility resulting from an error of a given magnitude falls with the level of consumption. In other words, at low levels of consumption a given level of disequilibrium along the intertemporal margin has a larger impact in terms of utility than the same level of disequilibrium at a high level of consumption. This property implies that at times when economic agents expect favorable conditions in the future, i.e., when they save little, i.e., times of expansions, they will also choose to be less informed. As a consequence the property implies that economic agents tolerate a higher level of intertemporal errors when they are optimistic about the future than they do when they are pessimistic about the future. Naturally, this implies that recessions should be on average shorter than expansions.

In this section the paper adheres to the assumption that all agents use the same priors. The decision making process of consumers starts with the decision on the quality of signals. Given the prior agents choose the quality according to the optimality condition (31). Then a specific signal is generated for each consumer. Naturally, not all consumers receive the same signal. Let $\nu^{i}$ be the signal for $x_{t+1}$ received by consumer $i$. Recall that consumer $i$ uses the signal to form the posterior distribution $F\left(x_{t+1} \mid \nu^{i}\right)$ and then chooses the optimal level of investment in physical capital. The level of investment can be obtained combining relationships (28) and (29) and is given by

$$
k_{t+1}^{i}=\frac{1}{2}\left(1-\left(q_{t} \nu^{i}+\left(1-q_{t}\right) E_{t} x_{t+1}\right)\right) \text {. }
$$

Note that the level of investment chosen by a specific agent is dependent on the specific signal she obtained. However, the aggregate level of investment 
remains deterministic, as the law of large numbers allows to establish $\int \nu^{i} d i=$ $q_{t} x_{t+1}+\left(1-q_{t}\right) E_{t} x_{t+1}$, and is given by

$$
k_{t+1}=\frac{1}{2}\left(1-\left(q_{t}^{2} x_{t+1}+\left(1-q_{t}^{2}\right) E_{t} x_{t+1}\right)\right) .
$$

Moreover, in equilibrium the level of investment is proportional to the true value $^{3}$ of $x_{t+1}$, i.e., $x_{t+1}=2 \psi k_{t+1}$. Therefore, the equilibrium evolution of variable $x$ assumes the form

$$
x_{t+1}=\frac{\psi}{1+\psi q_{t}^{2}}-\frac{\psi\left(1-q_{t}^{2}\right)}{1+\psi q_{t}^{2}} E_{t} x_{t+1} .
$$

Recall that all agents receive the same amount of income in the first period of their lives. Therefore, even though they save different fractions of their incomes, dependent on specific signals they draw, the average propensity to save in the aggregate remains constant and is equal to the level of investment in physical capital, i.e., $\beta_{t}=k_{t+1}$. Therefore, the level of output in terms of the price of the consumption good at time $t$ is given by

$$
y_{t}=\frac{\left(1-\phi \beta_{t}\right)}{\left(1-\beta_{t}\right)^{\alpha}} k_{t}^{\alpha} .
$$

Clearly, the level of output changes when $\beta_{t}$ changes. The latter may change for either a change in the expected value of $x_{t+1}$ or for a change in the precision of signals $q_{t}$. Naturally, whenever economic agents are ex ante optimistic about the future the smaller the fraction of income saved and the larger the equilibrium output. Similarly, a change in the informativeness of signals triggers a change in the level of savings and in the level of output. However, changes if they do happen are a result of an endogenous decision of rational agents.

\subsection{Dynamics}

The description of the equilibrium is now complete for a given set of prior distributions. Nevertheless, priors and the process of their formation have not been specified. Unfortunately, economic theory remains silent on the issue of the origin of priors. Therefore, there is no natural benchmark to turn to. The paper takes a subjective approach and assumes that priors are formed on the

\footnotetext{
${ }^{3}$ Observe that the aggregate investment can be used for perfect identification of variable $x_{\mathrm{t}+1}$ and hence economic agents by observing the level of investment $k_{\mathrm{t}+1}$ can learn the true value of $x_{\mathrm{t}+1}$. Naturally, if agents learn the true value of $x_{\mathrm{t}+1}$ then they can use it in the process of expectation formation and they would behave as if they had perfect foresight ability. This shortcoming can be addressed in either of the two ways. First of all, it can be assumed that information on aggregate variables arrives with a lag and hence $k_{\mathrm{t}+1}$ cannot be used for identification of $x_{\mathrm{t}+1}$. Alternatively, it could be assumed that agent $i$ receives a fraction $\omega_{\mathrm{i}}$ of economy wide profits where $\int \omega_{\mathrm{i}} d i=1$ and $\omega_{\mathrm{i}}$ is unknown and random. Then $\omega_{\mathrm{i}} x_{\mathrm{t}+1}$ becomes the relevant variable and expectations must be formed with regard to $\omega_{\mathrm{i}} x_{\mathrm{t}+1}$ rather than $x_{t+1}$ and then the overall level of investment stops being fully informative. The paper does not follow this alternative approach in order not to expand the dimensionality of the model.
} 
basis of past experience. Specifically, it is assumed that economic agents observe data up to $T$ periods into the past and based on these observations design a predictor. Then they use the predictor on past data and calculate prediction errors. Finally priors are formed from the predictor and the prediction errors.

Observe that in systems that converge to an equilibrium currently observed values become, by definition, with time better and better predictors of future variables. Therefore, it is natural to start with priors formed from a very simple predictor that approximates future value with currently observed values. In particular, this simple predictor approximates the value of $x_{t+1}$ with $x_{t}$. Therefore, the expected value of $x_{t+1}$ is simply equal to $x_{t}$, i.e., $E_{t} x_{t+1}=x_{t}$. The variance is equal to the variance of errors, $\varepsilon_{t-i}=x_{t-i+1}-x_{t-i}$, made by the predictor on past data. Under these assumptions of priors formation the dynamic equation of $x_{t}$ takes the form

$$
x_{t+1}=\frac{\psi}{1+\psi q_{t}^{2}}-\frac{\psi\left(1-q_{t}^{2}\right)}{1+\psi q_{t}^{2}} x_{t},
$$

as $E_{t} x_{t+1}=x_{t}$. The optimal quality of signal satisfies (31). Dynamic properties depend on the magnitude of $\psi$. If $\psi$ is smaller than 1 in absolute value then the level of capital stock and $x_{t}$ converge to an equilibrium, whereas if $\psi$ is greater than 1 in absolute value then the level of capital stock and $x_{t}$ follow explosive paths. The paper analyses the two cases in turn.

\section{Case 1 Let the parameters of the model be such that}

$$
\psi<1
$$

In this case $x$ and consequently the level of capital stock follow a path that converges to an equilibrium irrespective of a given choice of $q_{t}^{2}$. In other words, even if agents choose, along the equilibrium path, not to learn and form expectations in an adaptive manner the economy converges to an equilibrium. Moreover, convergence implies by definition that with time the distance between $x_{t+1}$ and $x_{t}$ approaches zero, i.e., $\varepsilon_{t-i} \rightarrow 0$ and $\sigma_{x_{t+1}}^{2} \rightarrow 0$. This means that as time progresses it pays more and more to form expectations in an adaptive manner, i.e., $q_{t}^{2} \rightarrow 0$ as $t \rightarrow \infty$. Therefore, as long as condition (34) is met $x$ and consequently the level of capital stock converge to an equilibrium and the economy is stable in the long run. The long run level of capital stock and the long run level of output are given by

$$
\begin{aligned}
k^{*} & =\frac{1}{2(1+\psi)} \\
y^{*} & =\frac{\left(1-\phi \beta^{*}\right)}{\left(1-\beta^{*}\right)^{\alpha}} k^{* \alpha},
\end{aligned}
$$

where $\beta^{*}=k^{*}$. Figure (3) depicts the evolution of the level of output in an economy when condition (34) is met.

It is clear that in this case the economy settles into a steady state in the long run and only exogenous shocks can cause fluctuations in macroeconomic 


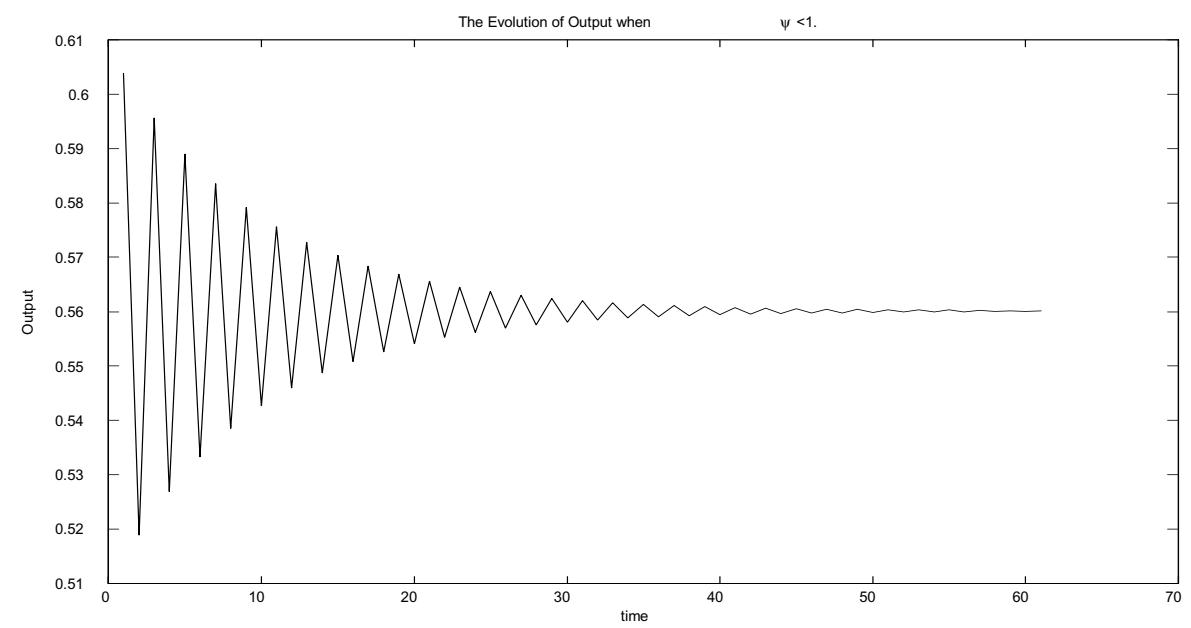

Figure 3: The Evolution of Output when $\psi<1$.

variables. The situation is different when condition (34) is violated. This case is dealt with next.

Case 2 A ssume that the parameters of the model satisfy the following inequality

$$
\psi>1
$$

i.e., assume that whenever agents choose to form expectations in an adaptive manner the level of capital stock, and hence the marginal propensity to save, follow an explosive path. ${ }^{4}$

Condition (35) implies that at any time the economy can be in either of two regimes. For $q_{t}^{2}$ sufficiently close to one it follows a process that converges to an equilibrium, i.e., the economy could be in a convergence regime. On the other hand for $q_{t}^{2}$ sufficiently close to zero the economy follows a process that does not converge to an equilibrium, i.e., the economy is in a divergence regime. Figure (4) illustrates sample dynamics in the two regimes.

In general, the economy could be in either of the two regimes depending on the precise value of $q_{t}^{2}$. Recall that $q_{t}^{2}$ does not constitute a parameter of the economy, but it depends on actions taken by economic agents and is itself determined as an equilibrium outcome. In particular, if economic agents choose $q_{t}^{2}$ to be large enough then the economy will follow a convergent path, on the other hand, if they choose $q_{t}^{2}$ to be small then the economy will proceed on a divergent path.

\footnotetext{
${ }^{4}$ Assumption of case 2 can be derived rather than imposed in a model in which optimization costs accrue in the form of forgone profits rather than in the form of utility costs.
} 

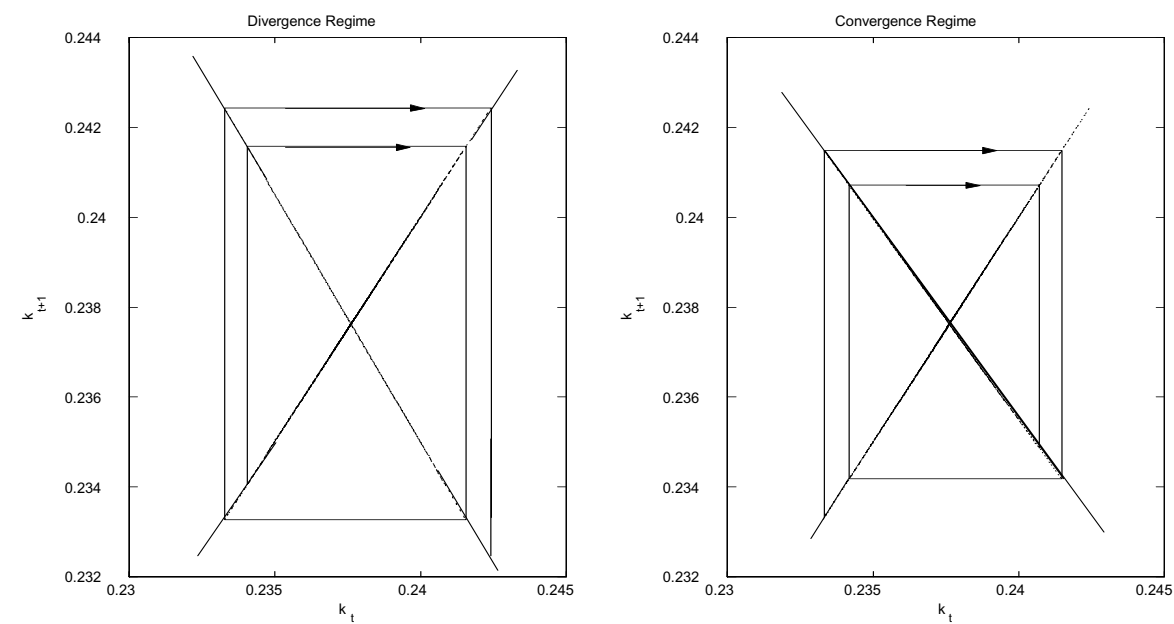

Figure 4: The Evolution of Physical Capital in Convergence and Divergence Regimes.

It is relatively straight forward to establish that as long as $\psi>1$ the economy does not settle down into a steady state. The reasoning is simple and assumes first the opposite. If the economy were to settle into a steady state then at some point the predictor would become relatively efficient and errors made with the predictor and their variance would be arbitrarily close to zero. Therefore, learning would become suboptimal and the quality of signal chosen would be eventually zero, i.e., $q_{t}^{2}=0$. However, with $q_{t}^{2}$ set to zero $x_{t}$ would follow a divergent path and no rest point would be attained. Hence a contradiction. It remains to establish that dynamic variables will not grow or keep diminishing for ever, i.e., it needs to be shown that the lack of a steady state implies equilibrium oscillations. In economic terms variable $x_{t+1}$ cannot grow for ever for its growth requires on one hand high investment as $x_{t+1}=2 \psi k_{t+1}$,i.e., future profits are increasing in the productive capacity of the economy, and on the other hand discourages investment as indicated by equation (32) high expected future income leads to small savings. Similar argument applies to the case when $x_{t+1}$ where to keep falling. Technically, the eigenvalue in the system (??) is negative hence the path the economy follows must be oscillatory.

In general the dynamic properties of the process followed by $x_{t}$ depend on the magnitude of the coefficient preceding $x_{t}$. For $q_{t}^{2}$ sufficiently high the coefficient is necessarily less than one and $x_{t}$ converges to an equilibrium. On the other hand if $q_{t}^{2}$ is close to zero then the coefficient is higher than one and $x_{t}$ does not converge to an equilibrium. Therefore, depending on the magnitude of $q_{t}^{2}$ the economy follows either a divergent or a convergent path. Naturally, $q_{t}^{2}$ is chosen in equilibrium and the equilibrium choice determines the characteristics of the underlying equilibrium process. Observe that whenever the economy follows a 

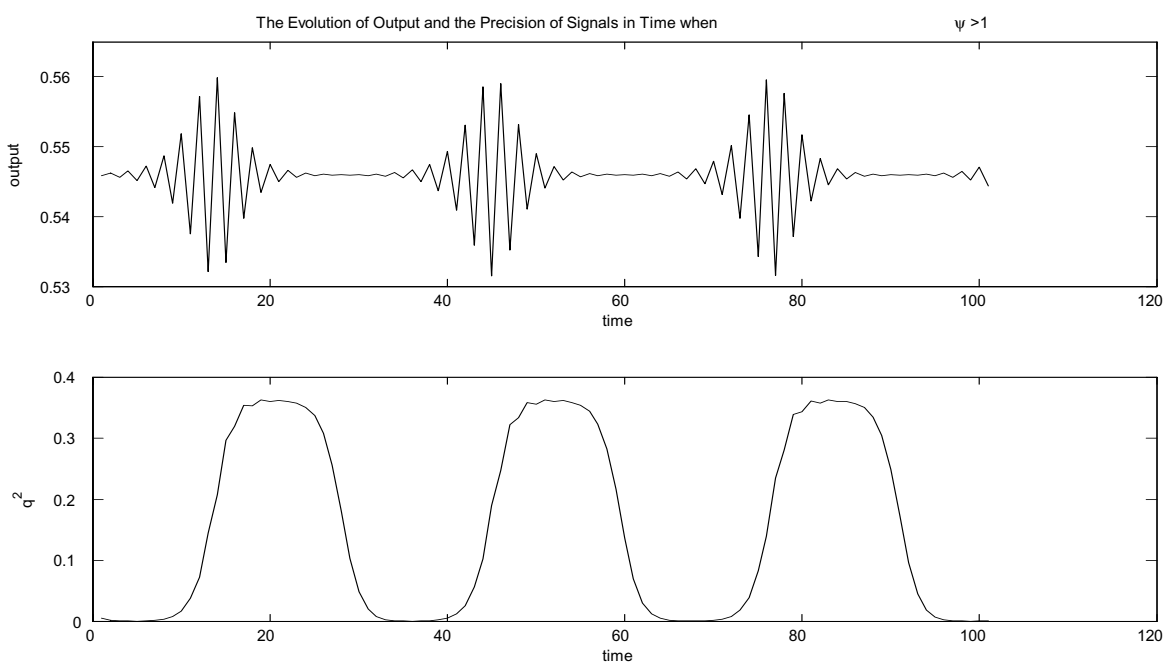

Figure 5: The Evolution of Output and the Precision of Signal in Time when $\psi>1$.

divergent path errors made with the naive predictor become large and their variance becomes high, i.e., the predictor becomes less and less reliable. Economic agents fearing sizable losses due to suboptimal behavior along the intertemporal margin decide to learn and purchase informative signals, i.e., they, as equation 31 indicates, increase the value of $q_{t}^{2}$. This, however, changes the nature of the dynamic process of $x_{t}$. Specifically, $x_{t}$ is put on a convergent path. Therefore, errors made with the naive predictor become smaller. Expectations based on the naive predictor do not lead to serious inefficiencies along the intertemporal margin and allow to save on the information gathering and processing costs. Consequently economic agents turn towards the naive predictor and stop learning. However, as a result the nature of the dynamic process is changed again and the economy enters a divergence regime. This leads to a loss of accuracy of the naive predictor and learning starts again. The process continues and the economy permanently oscillates between convergence and divergence regimes and never settles into a steady state. Figure (5) presents sample dynamics.

The paper up to this point has in effect limited the set of feasible expectation formation technologies to convex combinations of perfect foresight expectation and a naive expectation. Specifically, priors have been assumed to be formed with a very simple predictor. However, the assumption may be too restrictive. It is reasonable to assume that learning, simple trend and pattern extraction, based on past realized data does not involve significant costs. The paper, therefore, relaxes the previous restriction and permits economic agents to select expectation formation technologies from a richer set.

Specifically, it is assumed that economic agents can freely process informa- 
tion up to $T$ periods into the past. Analysis of past data allows economic agents to identify predictors. These predictors are in turn used to design priors. Priors are obtained by applying predictors to past data and assuming that true errors are distributed according to the distribution formed by residuals. For notational simplicity let the underlying dynamic equation be expressed as

$$
x_{t+1}^{\prime}=-\frac{\psi\left(1-q_{t}^{2}\right)}{1+\psi q_{t}^{2}} E_{t} x_{t+1}^{\prime}
$$

where $x_{t}^{\prime}=x_{t}-\frac{\psi}{1+\psi}$.

Let $f\left(x_{t}^{\prime}, x_{t-1}^{\prime}, \ldots, x_{t-K+1}^{\prime}\right)$ be a predictor of $x_{t+1}^{\prime}$ obtained on past data $\left\{x_{t}^{\prime}, x_{t-1}^{\prime}, \ldots, x_{t-T}^{\prime}\right\}$. Specifically, let $f()$ to be of a simple linear form with geometric weights

$$
f\left(x_{t}^{\prime}, x_{t-1}^{\prime}, \ldots, x_{t-K+1}^{\prime}\right)=\Sigma_{i=1}^{K} a(i) x_{t-i+1}^{\prime},
$$

where $a(i)=a(1) \omega^{i-1}$ for $i \in\{2, \ldots, K\}, \omega$ is a constant and the weights sum up to one. Moreover, let

$$
\varepsilon^{j}=x_{t+1-j}^{\prime}-\Sigma_{i=1}^{K} a(i) x_{t-j-i+1}^{\prime}, j \in\{1, . ., T-K\}
$$

be the errors obtained on past data with the predictor. The prior is formed using the predictor of $x_{t+1}^{\prime}$ and assuming that potential errors are distributed according to the distribution of the residuals. Under these assumption the evolution of variable $x_{t}^{\prime}$ follows the process ${ }^{5}$

$$
x_{t+1}^{\prime}=-\frac{\psi\left(1-q_{t}^{2}\right)}{1+\psi q_{t}^{2}} \Sigma_{i=1}^{K} a(i) x_{t-i+1}^{\prime}
$$

where the quality of signals $q_{t}^{2}$ is given by equation (31.)

As shown by Chiarella and He [11] the dynamic properties of equation (37) depend on the magnitude of the coefficients. Specifically a sufficient condition for lack of stability is given by

$$
2 \frac{\psi\left(1-q_{t}^{2}\right)}{1+\psi q_{t}^{2}} a(1)>1+\frac{\psi\left(1-q_{t}^{2}\right)}{1+\psi q_{t}^{2}} .
$$

Observe that were convergence to occur then the quality of signals would be eventually arbitrarily close to zero and the above condition would simplify to $2 \psi a(1)>1+\psi$. Moreover, for $\omega$ small enough the condition is necessarily satisfied. Therefore, convergence cannot occur. The figure (6) presents sample dynamics when economic agents form expectations according to (36).

\footnotetext{
${ }^{5}$ Note that the predictor can be biased. If this were the case it would be natural to modify the predictor with the bias $\frac{1}{T-K} \Sigma_{j=1}^{\top}-\mathrm{K} \varepsilon_{\mathrm{t}+\mathrm{j}-1}$. Note, however, that if convergence were to occur the bias would be arbitrarily close to zero, hence, it would become negligible and its presence would not change the results.
} 

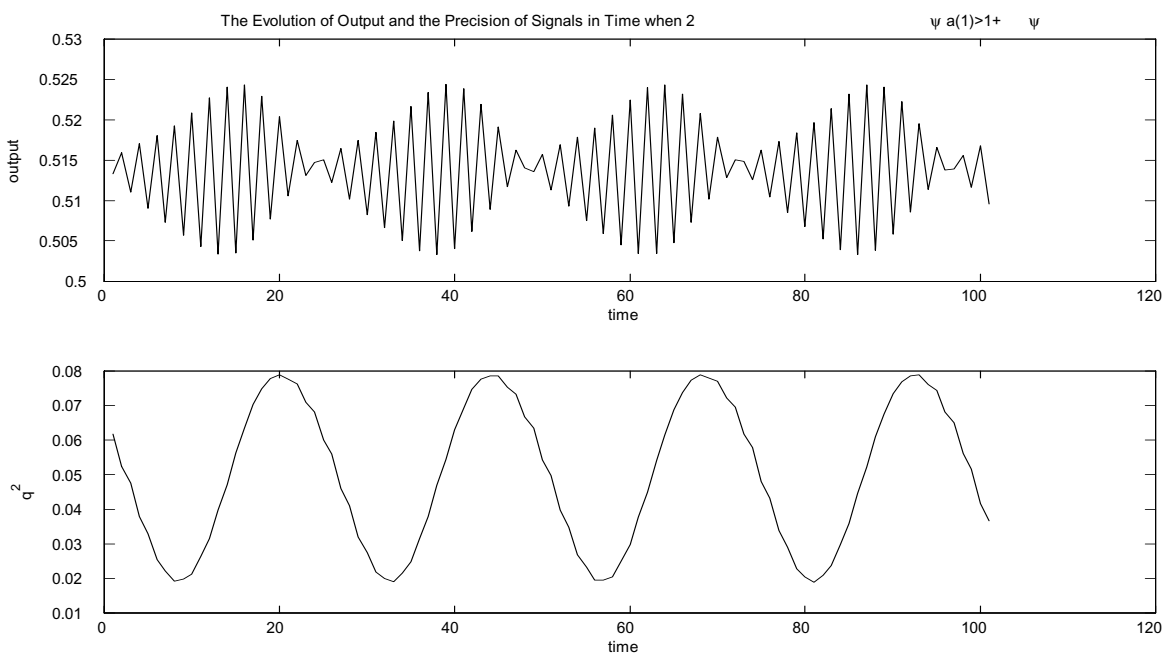

Figure 6: The Evolution of Output when $2 \psi a(1)>1+\psi$.

In summary, the economy does not settle into a steady state. The path it follows is oscillatory and is chosen in equilibrium. Specifically, the form of expectation formation is the key determinant of the path. The quality of signals purchased determines the size of the intertemporal errors. Moreover, it defines the characteristic of the underlying equilibrium dynamic equation (33). If agents choose to be relatively well informed, $q_{t}$ close to one, then the coefficient in front of $E_{t} x_{t+1}^{\prime}$ is less than one. This implies that the economy follows a convergent, albeit oscillatory, path, which terminates in a stable, given a high choice of $q_{t}$, steady state. However, if complete convergence were to occur priors would become more informative. Specifically past realized values would have to be close to the true realized value and the variance would become arbitrarily small. Moreover, the quality of signals depends on the variance of the underlying prior. Therefore, economic agents would stop learning as the priors would be sufficient to predict the future nearly with certainty and learning is costly. This, however, would change the nature of the law of motion of variable $x^{\prime}$. For $q_{t}$ low enough, when there is no learning, the law of motion describes an explosive path. Therefore, convergence would lead economic agents to choose not to learn, but that would push the economy out of the convergence regime and would put it on an explosive path into a divergence regime. This would, however, ruin the informativeness of priors, their variance would increase, and would again make agents learn. However, learning would again lead to convergence and the cycle would repeat itself indefinitely. In equilibrium the economy bounces back and forth between two regimes. Economic agents either learn and this leads to convergence or rely on past observations and this leads to divergence. In equilibrium, the two regimes alternate. 


\subsection{Inferences from Past Data}

Rational expectations approach to modelling decision making under uncertainty defines a benchmark in economic theory. In a very minimalist sense the rational expectations approach assumes that economic agents use the true distributions functions of the underlying variables in the decision making process. Consequently, the approach assumes that economic agents know the "model," i.e., are aware of the structure of the economy they operate in. The intuitive justification for the assumption invokes the law of large numbers, which allows to identify the relevant distribution functions and the interdependence between economic variables.

Economic literature normally imposes exogenous uncertainty on deterministic models. Such an approach is consistent with the assumption of rational expectations. Indeed, time evolving uncertainty resolution should eventually identify the true distribution functions as these are not affected by behavior of economic agents. In other words, even if economic agents at some point use incorrect distributions functions they are eventually able to identify the frequencies of all states of nature as these are not affected by their actions based on incorrect distributions. Consequently, economic literature nearly never focuses on the approach path towards a given rational expectations equilibrium, i.e., nearly universally starts by assuming that learning, if any, must have already occurred. Naturally, the route followed by the literature is sound and consistent, however, it does not comprise all possibilities.

In the model of this paper there are no stochastic disturbances at all. All variables are generated by deterministic processes. Therefore, the issue of economic agents knowing the true distribution functions becomes superfluous. However, it still remains to be verified whether it is reasonable to assume that economic agents know the "model."

The underlying dynamic equation in the model takes the form

$$
x_{t+1}^{\prime}=-\psi x_{t+1}^{\prime} e
$$

Naturally, the true realized value of $x_{t+1}^{\prime}$ depends on expectations formed at time $t$ with regard to variable $x_{t+1}^{\prime}$. Therefore, the realized outcome in period $t+1$ depends on actions taken by economic agents at time $t$. This differs the model of this paper from the benchmark normally present in the literature. The difference affects in a profound manner the learning process. In the current context errors affect the realized values whereas in the main stream of the literature they do not. Therefore, economic agents in the learning process must take into account the fact that their mistakes affect equilibrium outcomes.

In a special case when economic agents form expectations given a prior $F_{x_{t+1}^{\prime}}$ formed from a naive predictor and a signal of quality $q_{t}^{2}$ the underlying process takes the form

$$
x_{t+1}^{\prime}=-\psi \frac{\left(1-q_{t}^{2}\right)}{1+\psi q_{t}^{2}} x_{t}^{\prime}
$$

and for $q_{t}^{2}$ large enough it is a convergent process. Naturally, data generated by 
the above process allow for a perfect identification of all relevant coefficients, i.e., allow economic agents to learn the model. However, the shape of the model depends on the specific form of the expectation formation technology. Therefore, if economic agents were to use their knowledge of the model in the process of expectation formation they would change the nature of the model. Specifically, if economic agents were to start forming expectations according to the true model then the underlying equilibrium equation would take the form

$$
x_{t+1}^{\prime}=-\psi^{2} \frac{\left(1-q_{t}^{2}\right)}{1+\psi q_{t}^{2}} x_{t}^{\prime},
$$

i.e., the process would change. Naturally, the new process is also perfectly identifiable from data, however, an attempt to use the new model for assessments of $x_{t+1}^{\prime}$ would change the model again. In general after $i$ steps of learning of procedure the "true" model would take the form

$$
x_{t+1}^{\prime}=(-\psi)^{i} \frac{\left(1-q_{t}^{2}\right)}{1+\psi q_{t}^{2}} x_{t}^{\prime} .
$$

Not only the process would be different from all previous processes, but also for $i$ large enough the coefficient in front of $x_{t}^{\prime}$ must be necessarily greater than one. Therefore, the process of learning not only fails to identify a rule that would allow economic agents to form expectations correctly, but also destabilizes the economy. Note that the initial process led to a steady state whereas the process obtained after $i$ stages of learning does not.

The above example illustrates that while past data can be used for identification of analytic relationships the relationships need not have practical importance as an attempt to use a relationship changes the nature of the relationship and invalidates the original relationship. The model, thus, provides a version of the Lucas Critique [31] in the context of expectation formation and its impact on the coefficients of the underlying model.

\section{Policy Considerations}

Professional economists while considering high frequency fluctuations in macroeconomic variables to be a matter of fact differ as to their significance. Some economists maintain that oscillations while present are either virtually harmless, most notably Lucas [30], when one considers their impact on welfare or adhere to the view that any attempts to counteract them must necessarily be welfare worsening, RBC theory proponents. Therefore, they argue, governments should restrain themselves from activists policies since, given the presence of lags and uncertainty, any policy aimed at mitigating fluctuations is bound to cause more harm than good. On the other hand there are plenty of arguments, most recent those of Gali, Gertler and Lopez-Salido [19] and of Caballero and Hammour [8], that note potential sizable costs of recessions, and at the minimum, advocate caution in dealing with movements in macroeconomic variables. Furthermore, 
in practice governments almost always resort to active policies and rarely rely on the approach of benign neglect. This paper, while not being equipped to resolve fully the ongoing dispute, delivers several predictions and delivers clear policy recommendations.

First of all note that there are imperfections introduced into the paper by assumption. The assumption of imperfect competition in itself calls for an active intervention. Similarly, the fact that an OLG model is used as a benchmark allows for the possibility of dynamic inefficiency and makes potentially government policy viable. The paper, however, takes these two imperfections as given and does not attempt to provide prescriptions that could counteract them. The paper shows that fluctuations in macroeconomic variables are costly and focuses only on measures that could limit the impact of equilibrium fluctuations on welfare.

Observe that whenever the error of perception is positive economic agents are overoptimistic. This overoptimism affects the amount saved in equilibrium and leads to intertemporal welfare redistribution. First of all overoptimism decreases saving and increases current output and the welfare of current old. Moreover, it is ex post costly to the currently young since they eventually find out that they were overly optimistic and that they under saved. Furthermore, it is costly to the members of the future generations since they have too little capital to work with. Similarly, overpessimism leads to intertemporal welfare shifts harming currently alive and unnecessarily rewarding the future generations. Therefore, inability to foresee the future perfectly leads to suboptimal outcomes and makes government intervention viable.

Fluctuations in this paper are an outcome of aggregate demand disturbances. The disturbances result from the fact economic agents revise, in an individually rational manner, their expectations. Specifically, fluctuations are due to the fact that economic agents willing to economize on information gathering and processing costs choose not to foresee the future correctly. Naturally, a very simple policy can restore the first best outcome. The government should gather and process information and should endow the public with the best possible estimates of the future economic variables. This simple strategy can fully eliminate oscillations in the framework of this paper. In practice, however, this strategy need not be a realistic option as the viability of the option stems from the fact that the paper uses a representative agent framework. In general, in an environment with heterogenous agents the government need not have the capacity to estimate future income streams of all agents and the basic strategy must be replaced with second best instruments.

Tax cuts and government spending remain the two major policy instruments. Moreover, during recessions attempts to restore consumer confidence are a key component of stabilization programs. Implicit for these policies is the assumption that for some reason consumers choose not to spend the amount they ought to. However, the assumption is inconsistent with the rational expectations paradigm. The framework of this paper allows to justify that these policies are indeed welfare improving and consistent with consumer behavior. Fluctuations arise because expectations held by economic agents are based on information 
sets being subject to normal decision making and as a result economic agents can save either too little or too much as compared to the full information case. The approach of counter cyclical deficits is the most natural instrument that can influence the level of savings and physical capital formation. The government can eliminate cycles and increase welfare by running a deficit when economic agents are overly pessimistic and maintaining a surplus when economic agents undersave. In general, a bond issue, or purchases of physical capital, in the amount of

$$
b_{t}=\Delta k_{t}=k_{t}-k_{t}^{P F}
$$

restores the full information equilibrium. Again this assumes that the government is fully aware of the price value of $k_{t}^{P F}$, which is seldom the case in practice and, thus makes the policy ineffective. Nevertheless, any form of an automatic stabilizer, such as a proportional tax, can limit the scope of inefficiencies resulting from expectations revisions. Similarly, measures that boost consumer confidence during recessions can be welfare improving as these increase the level of consumer spending and bring the economy to the full information level of output.

Output growth that exceeds the speed of expansion of the productive capacity of the economy eventually leads to an adjustment in the price level. Therefore, movements of the price level can serve as signals for policy decisions. Specifically, policy makers routinely choose to follow restrictive policies when price increases. Naturally, such a policy helps to bring the level of output to its potential, however, it remains orthogonal to economic theory as departures of output above or below its potential are not supported by the assumption of rational decision making. The model developed in this paper not only shows that counter cyclical policy indeed helps to restore the potential level of output, but it also confirms viability of the policy. The model exhibits standard demand side disturbances properties. In particular, it captures a positive correlation between price and demand increases. Specifically, several steps of algebra allow to establish

$$
\left(p_{t}-\bar{p}\right)\left(y_{t}-\bar{y}\right) \sim\left(\bar{\beta}-\beta_{t}\right)^{2},
$$

where variables with an upper bar denote the variables that would materialize under perfect foresight. Clearly, a price that exceeds $\bar{p}$ is indicative of output exceeding the potential and calls for a restrictive policy action as not fully informed agents overspend. On the other hand a price that is below $\bar{p}$ signals a slump in demand and justifies an expansionary mode as economic agents hold too pessimistic expectations. Therefore, policy makers can observe movements in the price level and base their decisions on price level changes. The model is, thus, consistent with practice normally observed in reality as it justifies a restrictive policy move in the case of inflation.

Blanchard [4] argued that the 1990/91 recession was an outcome of a consumption shock. The shock itself is left unexplained. However, a revision of overly optimistic consumption plans is listed as a potential cause of the shock. Naturally, the argument allows implicitly for the possibility of economic agents being unable or choosing not to follow optimal consumption plans. Similarly, 
occasional dramatic buildups of consumer credit are thought to signal some form of irrational behavior on the part of consumers. All these possibilities are considered to lead to output growth that is not justified by corresponding growth of the productive capacity of the economy. The discrepancy, if it exists, is not sustainable and normally leads to active policy measures. Clearly, policy design invokes the concepts of overheating and output gap. Yet, economic theory has not given any formal meaning to these terms. The framework of this paper allows to define these concepts in a natural manner. Note that the optimal amount invested at time $t$ differs from the amount actually invested. The difference, given by,

$$
k_{t}^{P F}-k_{t}=\frac{1}{2}\left(1-q_{t}^{2}\right)\left(E_{t} x_{t+1}-x_{t+1}\right)
$$

accounts for consumer overconfidence. When the above quantity is positive consumers save too little and the economy departs from its trend upwards and operates above its potential. In such a situation the economy can be thought as being overheated as the temporary spending boost cannot be sustained. Moreover, when the actual level of investment matches the level of investment under perfect foresight then the level of output can be thought as being equal to its potential. Revision of expectations either upwards or downwards lead to either an upward or a downward deviation of output. These deviations allow actual output to differ from potential output. The difference can be naturally interpreted as a measure of output gap.

In general the model allows to define several measures of output. First of all, the model defines the equilibrium level of output. The level is determined by the supply side characteristics and by expectations, which influence the composition of aggregate demand. In addition, there are other concepts. Specifically, the model defines the level of output that would materialize if agents always formed expectations using the best available expectation formation technology. The level can be interpreted as the natural level of output or the potential level of output. Moreover, the level of output that would exist under the assumption of perfect foresight need not be, and typically is not, identical with the average level of output. Finally, there is a level of output that would materialize if economic agents chose to form expectations in a perfect foresight manner at a given point in time rather than the way they actually chose to. Note that, this measure is not the same as the level of output generated by an economy in which all agents form expectations using perfect foresight technology at all points in time. This is due to the fact that any change in expectations not only changes the level of consumption, but also the level of investment. Figures (7) and (8) present samples of measures.

In summary, expansions and recessions exist because consumers' expectations are either overly pessimistic or overly optimistic. Overoptimism leads to low savings and to a higher level of output than the potential level of output, while overpessimism leads to high savings and to a level of output below the potential level of output. The deviations of output from the potential level of output lead to intertemporal welfare redistribution. Therefore, countercyclical 

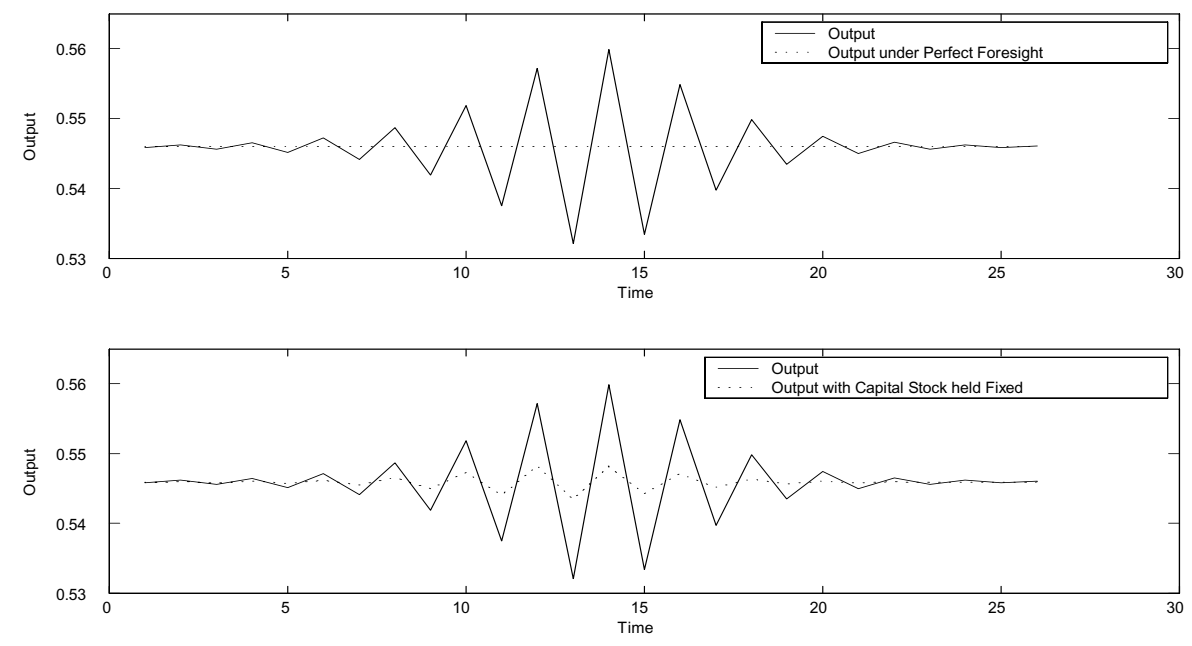

Figure 7: The Evolution of Output, Potential Output, and Output with Capital Stock Held Fixed in Time.
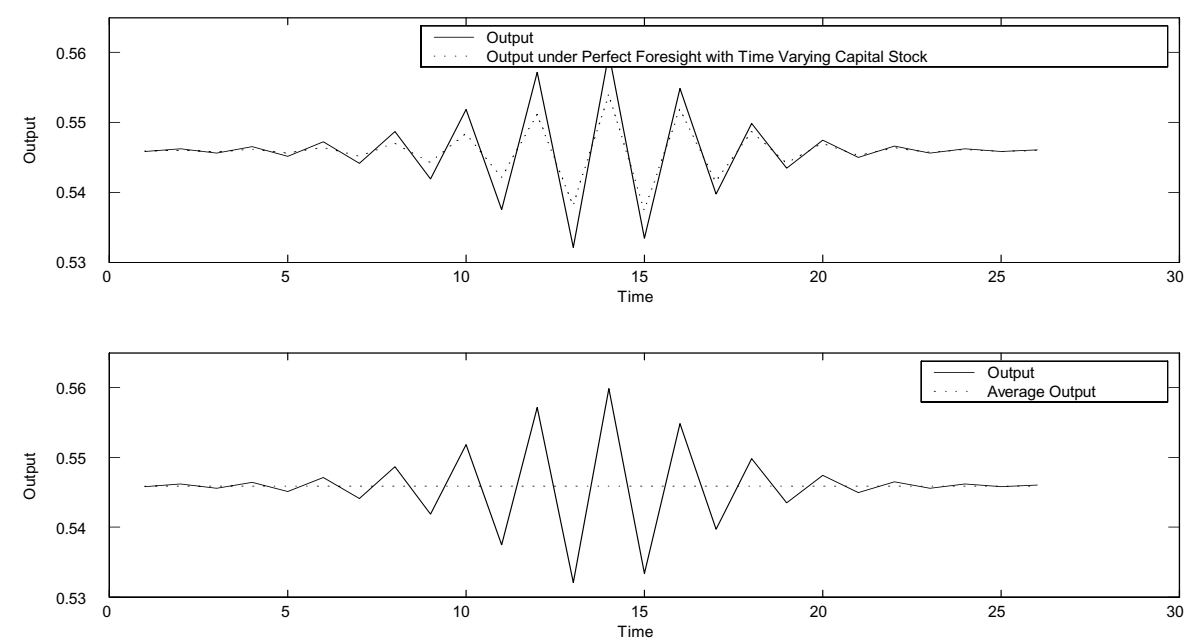

Figure 8: The Evolution of Output, Output under Perfect Foresight with Time Varying Capital Stock, and the Average Level of Output. 
policy leading to smoothing of deviations of output from long run trend can limit welfare losses.

\section{Conclusions}

The paper recognizes that expectations and the process of expectation formation are not, in principle, imposed on the economy, but rather that they are subject to the discretion of economic agents and are determined as a part of equilibrium. Consequently, the paper develops a framework in which agents at any point in time decide in an individually rational manner what expectations to hold. Expectations are derived from specific expectation formation technologies and are chosen on the basis of the level of utility they are expected to yield. The set of feasible expectation formation technologies comprises both a perfect foresight technology and "naive," based on past experience, expectation formation technologies. The perfect foresight technology allows for optimal savings decision whereas the "naive" expectation formation technologies need not suffice to guarantee efficiency along the intertemporal margin. The choice of an expectation formation technology is not trivial as the paper assumes that expectation formation is costly. Specifically, the more accurate a given expectation formation technology is the higher its costs. Therefore, economic agents willing to attain efficiency along the intertemporal margin must pay a high expectation formation cost on the other hand those who choose to rely on past experience face the risk of suboptimal saving behavior, but save on information gathering and processing costs. Agents weigh the two costs and make informed decisions with the regard to the type of expectations they wish to hold.

While the assumption of Agents' discretion over expectations adds on to realism it also carries non trivial implications. The paper develops a model in which the economy follows an unstable dynamic equation when all agents choose to form expectations in an adaptive manner and follows a dynamic equation that settles into a rest point if economic agents choose to form expectations in a perfect foresight manner. This basic structure, as noted by Brock and Hommes [7], leads in a natural manner to endogenous fluctuations in macroeconomic variables. Specifically, the paper establishes that rational choice over expectations can lead to endogenous fluctuations in aggregate demand. Optimization over expectations makes agents alternate between better and worse expectation formation technologies depending on the distance from a potential rest point. The closer the economy is to a potential rest point the more current outcomes resemble future outcomes. Therefore, expectations based on naive expectation formation technologies allow for nearly optimal behavior along the intertemporal margin and at the same time do not involve any information gathering and processing costs. Naturally, rational agents on the approach path, where the economy is sufficiently stable, to a potential rest point choose to rely on coarser expectation formation technologies and eventually turn towards naive expectations. However, if all agents choose to form expectations in an adaptive manner the economy enters an unstable path and errors of perception become larger and 
larger. Eventually, economic agents must turn towards more robust expectation formation technologies as the loss in terms of utility resulting from large errors of perception outweighs information gathering and processing costs. However, this puts the economy on a convergent path and again the economy approaches a potential rest point. When the economy is sufficiently close to a rest point agents turn again towards adaptive expectation formation and the cycle repeats itself. As a consequence the economy oscillates between two distinctive regimes: a convergence and a divergence regime. Whenever, the economy is in the convergence regime agents form expectations in an adaptive manner this, however, pushes the economy into the divergence regime. Moreover, in the divergence regime agents form expectations in a nearly perfect foresight manner. This, however, introduces stability and pushes the economy back into the convergence regime. The cycle repeats itself and results in permanent and endogenous fluctuations in aggregate variables.

The paper is written is an explicit macroeconomic context. Specifically, the paper develops a general equilibrium model that comprises the Diamond [14] OLG model, the Blanchard and Kiyotaki [5] monopolistic competition paradigm, and the Brock and Hommes [7] framework of expectation selection as the three key ingredients. In the model the presence of monopolistic competition allows the composition of aggregate demand to affect aggregate variables, i.e., the model exhibits multiplier characteristics. In particular, the higher the fraction of income saved the lower the output and vice versa. In the context of the paper economic agents form assessments of their future income streams. An expectation of favorable conditions in the future leads through the intertemporal smoothing channel to low savings and in turn, through the multiplier effect, to high output, while an expectation of low future income increases savings and leads through the multiplier effect to low output today. Expectations, however, are not assumed to be exogenous. Quite the opposite the process of expectation formation is a part of the equilibrium and any shifts in expectations are equilibrium outcomes.

Moreover, the paper shows that the fact that expectations need not settle on a specific value even in the long run can be deeply rooted in economic properties of macroeconomic systems. Observe that equilibrium outcomes depend in part on the amount of resources available. In particular, future income depends on the future capital stock. Specifically, a higher level of capital stock implies, other things equal, a higher level of income. Furthermore, a high level of income in the future implies, ceteris paribus, low savings at the present. However, savings determine future capital stock. Therefore, low savings result in low capital stock and hence in a low income in the future. This basic mechanism illustrates that expectations of economic agents expecting favorable conditions in the future and saving little must necessarily be invalidated when the future actually arrives. The paper shows that if the ex post discrepancy is large enough then the existence of this basic natural negative feedback mechanism can lead to endogenous fluctuations in aggregate demand.

In addition, the paper delivers several predictions with the respect to policy prescriptions. It shows that the movements in aggregate output obtained 
within the framework of this paper constitute deviations from a long run trend and argues that government intervention can be welfare improving. Moreover, the paper quantifies the intangible notions of overheating, overborrowing, and output gap.

In summary, the paper gives an example of an equilibrium route towards endogenous fluctuations in aggregate demand. The fluctuations are the result of equilibrium actions taken by rational utility maximizing agents.

\section{R eferences}

[1] Akerlof, George A., and Janet L. Yellen, (1985.) "A Near-Rational Model of the Business Cycle, with Wage and Price Inertia." Quarterly Journal of Economics 100 (Supplement), pp. 823-838. Reprinted in Mankiw and Romer (1991.)

[2] Aghion, Philippe, Abhijit Banerjee, and Thomas Piketty (1999), "Dualism and Macro-Economic Stability," Quarterly Journal of Economics Vol 114 (4), pp. 1359-1397.

[3] Barlevy, Gady (1998), "Learning Costs and Delayed Adjustment," Northwestern University mimeo.

[4] Blanchard, Olivier-Jean (1993), "Consumption and the Recession of 19901991," American Economic Review Papers and Proceedings, May 1993, pp. 270-274.

[5] Blanchard, Olivier-Jean, and Nobuhiro Kiyotaki (1987), "Monopolistic Competition and the Effects of Aggregate Demand," American Economic Review, 77, pp. 647-66.

[6] Blanchard, Olivier-Jean (1977), "Essays on Fluctuations," MIT, Ph.D., Thesis 1977.

[7] Brock, William A., and Cars H. Hommes (1997), "A Rational Route to Randomness," Econometrica, Vol. 65, No 5, pp. 1059-1095.

[8] Caballero, Ricardo J. and Mohammad Hammour, (1998), "Macroeconomics of Specificity," Journal of Political Economy, 106(4), Augusts 1998, pp. 724767 .

[9] Chiarella, C. (1988), "The Cobweb Model, its Instability and the Onset of Chaos," Economic Modelling 5, pp. 377-384.

[10] Chiarella, C, and X. He (2000a), "Asset Pricing and Wealth Dynamics under Heterogeneous Expectations," School of Finance and Economics, University of Technology Sydney. Working Paper. 
[11] Chiarella, C, and X. He (2000b), "Dynamics of Beliefs and Learning under $a_{L}$-processes-the Homogeneous Case," School of Finance and Economics, University of Technology Sydney. Working Paper.

[12] Chiarella, C, and X. He (2000c), "Dynamics of Beliefs and Learning under $a_{L}$-processes-the Heterogeneous Case," School of Finance and Economics, University of Technology Sydney. Working Paper.

[13] Chiarella, C, and X. He (2000d), The Dynamics of the Cobweb when Producers are Risk Averse Learners, Physica-Verlag, pp. 86-100. in Optimization, Dynamics, and Economic Analysis, E.J. Dockner, R.F. Hartl, M. Luptacik and G. Sorger (Eds.)

[14] Diamond, Peter A., (1965), "National Debt in an Neoclassical Growth Model." American Economic Review, 55, pp. 1126-1150.

[15] Diamond, Peter A., (1982), "Aggregate Demand Management in Search Equilibrium," Journal of Political Economy 90 (October): pp 881-894.

[16] Evans, George (1985), "Expectational Stability and the Multiple Equilibria Problem in Linear Rational Expectations Models." Quarterly Journal of Economics 100, 4 (Dec.), pp. 1217-1233.

[17] Evans, George and Honkapohja, S. (1999), Learning Dynamics, chapter 7, pp. 449-542. in Handbook of Macroeconomics, Es. J.B. Taylor and M. Woodford.

[18] Evans, G., and G. Ramey (1992), "Expectation Calculation and Macroeconomic Dynamics," American Economic Review, 82, pp. 207-224.

[19] Gali, Jordi, Mark Gertler and J. David Lopez-Salido (2001), "Markups, Gaps, and the Welfare Costs of Business Fluctuations," mimeo.

[20] Grandmont, J.-M. (1998), "Expectations Formation and Stability of Large Socioeconomic Systems," Econometrica, 66, pp. 741-781.

[21] Grandmont, J.-M., and G. Laroque (1991), "Economic Dynamics with Learning: Some Instability Examples," in Equilibrium Theory and Applications: Proceedings of the Sixth International Symposium in Economic Theory and Econometrics, ed. by W.A. Barnett, B. Cornet, C. d'Aspremont, J. Gabscewicz, and A. Mas-Colell. Cambridge: Cambridge University Press, pp. $247-273$.

[22] Grandmont, J.-M. (1985), "On Endogenous Competitive Business Cycles," Econometrica, 53, pp. 995-1045.

[23] Guesnerie, R., and M. Woodford (1992), "Endogenous Fluctuations," in Advances in Economic Theory: Sixth World Congress, ed. by J.J. Laffont. Cambridge: Cambridge University Press. 
[24] Hommes, C. (1991), "Adaptive Learning and Roads to Chaos: The Case of the Cobweb," Economic Letters 1991, pp. 127-132.

[25] Hommes, C. (1994), "Dynamics of the Cobweb Model with Adaptive Expectations and Nonlinear Supply and Demand," Journal of Economic Behavior and Organization 24, pp. 315-335.

[26] Hommes, C. (1998), "On the Consistency of Backward-Looking Expectations: The Case of the Cobweb," Journal of Economic Behavior and Organization 33, pp. 333-362.

[27] Jousten, Alain (1998), "Consumer Behavior and Failure to Account for Risk," unpublished manuscript.

[28] Kalecki, Michal (1938), "The Determinants of Distribution of National Income," Econometrica, 6, pp. 97-112.

[29] Kiyotaki, Nabuhiro (1988), "Multiple Expectation Equilibria and Monopolistic Competition," Quarterly Journal of Economics, 102, pp. 695-714.

[30] Lucas, Robert E., Jr. (1987), Models of Business Cycle. Oxford: Basil Blackwell.

[31] Lucas, Robert E., Jr. (1976), "Econometric Policy Evaluation: A Critique." Carnegie-Rochester Conference Series on Public Policy 1: pp. 19-46.

[32] Matsuyama, Kinimori (1999), "Growing Through Cycles," Econometrica, 67, March 1999, pp. 335-347.

[33] Matsuyama, Kinimori (2001), "Growing Through Cycles in an Infinitely Lived Agents Economy," Journal of Economic Theory, 100, October 2001, pp. 220-234.

[34] Marcet, Albert and Thomas Sargent (1988), "The Fate of Systems with Adaptive Expectations," American Economic Review Papers and Proceedings, 78, May 1988, pp. 168-172.

[35] Marcet, Albert and Thomas Sargent (1989a), "Convergence of Least Squares Learning Mechanisms in Self-Referential Linear Stochastic Models," Journal of Economic Theory, 48, pp. 337-368.

[36] Marcet, Albert and Thomas Sargent (1989b), "Convergence of Least Squares Learning in Environments with Hidden State Variables and Private Information," Journal of Political Economy, 97, pp 1306-1322.

[37] Nerlove, M. (1958), "Adaptive Expectations and Cobweb Phenomena," Quarterly Journal of Economics, 73, pp. 227-240.

[38] Nyarko, Y. (1991), "Learning in Mis-Specified Models and the Possibility of Cycles," Journal of Economic Theory, 55, pp. 416-427. 
[39] Prescott, Edward C. (1986), "Theory Ahead of Business-Cycle Measurement." Carnegie-Rochester Conference Series on Public Policy 25 (Autumn): pp. 11-44.

[40] Shleifer, Andrei (1986): "Implementation Cycles," Journal of Political Economy 94, 6 (Dec.), 1163-1190.

[41] Reis, Ricardo (2003), "Inattentive Consumers," Harvard University, mimeo.

[42] Townsend, R. (1983): "Forecasting the Forecasts of Others," Journal of Political Economy, 91, 546-588. 